\title{
RESEARCH ON WORKING STABILITY OF A MINI EXCAVATOR BOOM HYDROSTATIC CONTROL SYSTEM
}

\begin{abstract}
A. Kosiara*
Abstract: The article stresses the desirability of using energy-saving hydraulic control systems in mobile earthmoving machines. This group of systems includes LS control systems (load sensing). LS systems, along with many of their advantages, are sometimes unstable in certain applications. The author tested the effectiveness of two methods known from the literature to increase the stability of a typical LS system. The article presents selected results from these tests along with conclusions.
\end{abstract}

Keywords: single bucket excavators, hydrostatic drive, work stability, energy-saving drive systems

\section{Introduction}

The control of single bucket excavator attachment is carried out using hydrostatic drives. In the case of small excavators, so-called mini excavators, these are usually simple systems powered by pumps with a constant geometric volume. With the increase in the weight of this class of industrial vehicles, the hydraulic drives, which are used by them are becoming more and more sophisticated and contain more and more advanced technical solutions. In medium and large excavators, pumps with variable geometrical volume are commonly used.

A characteristic feature of hydrostatic drive systems used to control manipulators of single bucket excavators is that one energy source (a pump) supplies many energy receivers (cylinders, hydraulic motors, etc.). Typically, the same hydraulic pump is used to power hydraulic cylinders mounted between: the body and the boom, the boom and the arm and the arm and the articulated bucket. The number of receivers currently supplied from one pump is variable and random to some extent. What is more, the power demand of a given receiver is not constant and depends on many factors changing over time. Therefore, the question arises what output flow and output pressure of the pump would be sufficient and how to control these parameters. It should be noted here that the energy consumption of the excavator depends on this control method (Szydelski, 1999). It is also worth emphasizing that the energy consumption of the excavator is a parameter to which more and more attention is paid. The reduction of energy consumption of working machines (including excavators) is being attempted in various ways, for example by: a) searching for structural solutions to minimize internal and external resistance of tracked undercarriages (Dudziński et al., 2017, Dudziński et al., 2016 and Czabanowski, 2011), b) development of systems for the recovery of mechanical energy accumulated in moving parts of working machines (Nishida et al., 2013), etc.

Various systems whose basic goal is to minimize the hydraulic power lost due to heating hydraulic oil have been developed for a long time. One of the best-known solutions of this type is the LS (Load Sensing) system used, for example, in hydraulic directional valves by Danfoss. The LS system can be used both in a hydrostatic system driven by a constant displacement pump and a variable displacement pump. The idea of this type of system is based on the dependence of oil pressure on the pump discharge line from the actual load of energy receivers. In this control method, all the pressures that are currently

Assoc. Prof. Andrzej Kosiara, PhD.: The Department of Off-Road Machine and Vehicle Engineering, Wrocław University of Science and Technology; Łukasiewicza 7/9; 50-371, Wrocław; PL, andrzej.kosiara@pwr.edu.pl 
required to drive individual receivers are compared with each other in order to find the largest one. The pump pressure is set at level which is slightly higher than the largest pressure determined.

As the LS control system has many advantages, it has been widely used in many hydrostatic drives. Sometimes, however, in special applications, hydrostatic systems with LS control are characterized by unstable operation. This article describes what remedies can be taken to increase the stability of the hydrostatic drive system with constant displacement pump and LS control. It also discusses the effectiveness of these methods.

\section{Test stand with measuring system}

The instability in the LS control system is intensified by the large inertia of the driven mechanism. Most often, the unstable operation of the LS system can be seen in the case of its use in the system for lifting and lowering loads or in the system for the rotation of a relatively large object by means of a linear hydraulic cylinder.

The unstable LS control system used in the tests was built for positioning the boom of a mini excavator. Its simplified diagram is shown in Fig. 1. During the experimental tests the following values were recorded: pressure in the outflow pipe (sensor No. 1), LS pressure (sensor No. 2), pressure in the pump discharge pipe (sensor No. 3), pressure in the cap end side chamber of hydraulic cylinder No. 14 (sensor No. 17), pressure in the rod end side chamber of hydraulic cylinder No. 14 (sensor No. 13), position of the piston rod in relation to the cylinder No. 14, control signal of the proportional directional valve No. 11.

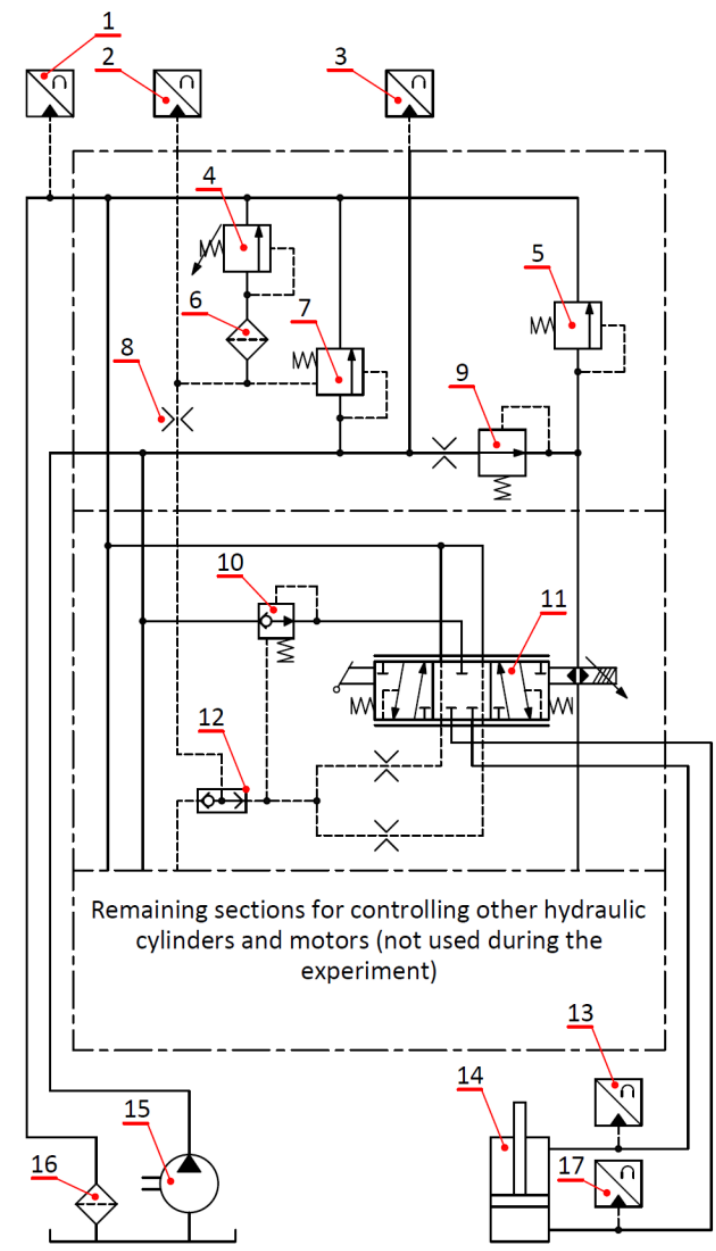

Fig. 1: Diagram of the hydraulic system used in experimental tests.

\section{Experimental tests}

In the first stage of experimental tests, measurements of the values mentioned in point 2 were carried out during unstable operation of the mini excavator boom position control system. The mini excavator's 
manipulator was not equipped with a working tool during these tests. The pressure pulsations which occurred in the cap end side chamber of the hydraulic cylinder are shown in Fig. 2. They were measured while lifting up the boom. Control signal fed to the directional valve was approximately equal to half the allowable maximum value.

Fig. 2 shows that unstable operation of the LS control system resulted in pressure oscillations. The amplitude and frequency of the oscillations were, respectively, 2.28 MPa and 3.7 Hz. The direct cause of the recorded phenomenon was the unstable operation of valve No. 7. The control system should be prevented against such situation by the throttling valve No. 8 (Merritt, 1967). Unfortunately, in this particular case its stabilizing role turned out to be insufficient.

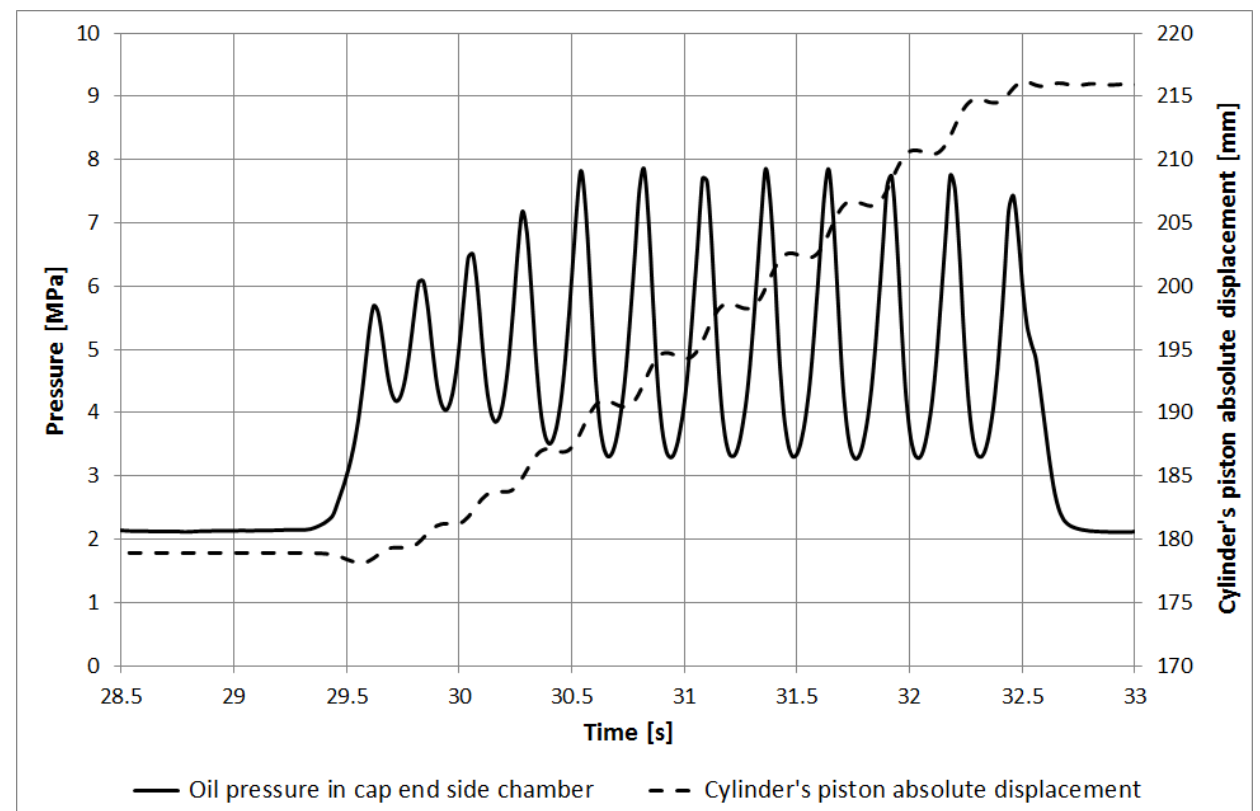

Fig. 2: Exemplary values, measured during unstable, non-modified LS control (description in the text).

The first of the tested ways to improve the dynamic properties of the tested system involved replacing the throttling valve No. 8 with a check valve. The change practically eliminated the unstable work in case where the tool was not attached to the manipulator. Mounting the bucket to the manipulator again resulted in the unstable operation of the LS system. This is shown in Fig. 3. Oil pressure pulsations of $3.63 \mathrm{~Hz}$ and an amplitude of $0.18 \mathrm{MPa}$ appeared in the system.

The tested hydraulic system was built using PVG 32 proportional directional valve. The manufacturer of this valve - Danfoss company - proposes in the situation of unstable operation of the LS system replacing the standard spool of the valve with a special patented design. The author decided to try the effectiveness of this method. The conventional spool was replaced with 157B7010 counterpart. After replacing the spool, the tests were repeated for both the case of the unloaded manipulator and the manipulator loaded with the tool. In both cases the LS system worked stably as shown in Fig. 4.

\section{Summary}

The article presents two methods known from the literature for increasing the stability of the LS control system. Their effectiveness was confirmed experimentally. The first of the methods consisting in replacing the throttling valve No. 8 with a check valve allows to increase the stability of the system in a lower degree than the other. The tests have shown that it can be useful if the instability is low. The second method, which consists in replacing the conventional spool of the directional valve with a specially designed one, can be used even when the instability is very high. Unfortunately, the disadvantage of the use of the spool with a special design (main spool with pressure control) is the fact that the deadband of the directional valve as well as the speed of the controlled cylinder at particular control signal fed to the directional valve may become load-dependent. Therefore, this solution should be used as a last resort. If it is chosen, it is advisable to introduce additional modifications in the system at the same time to reduce the impact of the load on the control process. 


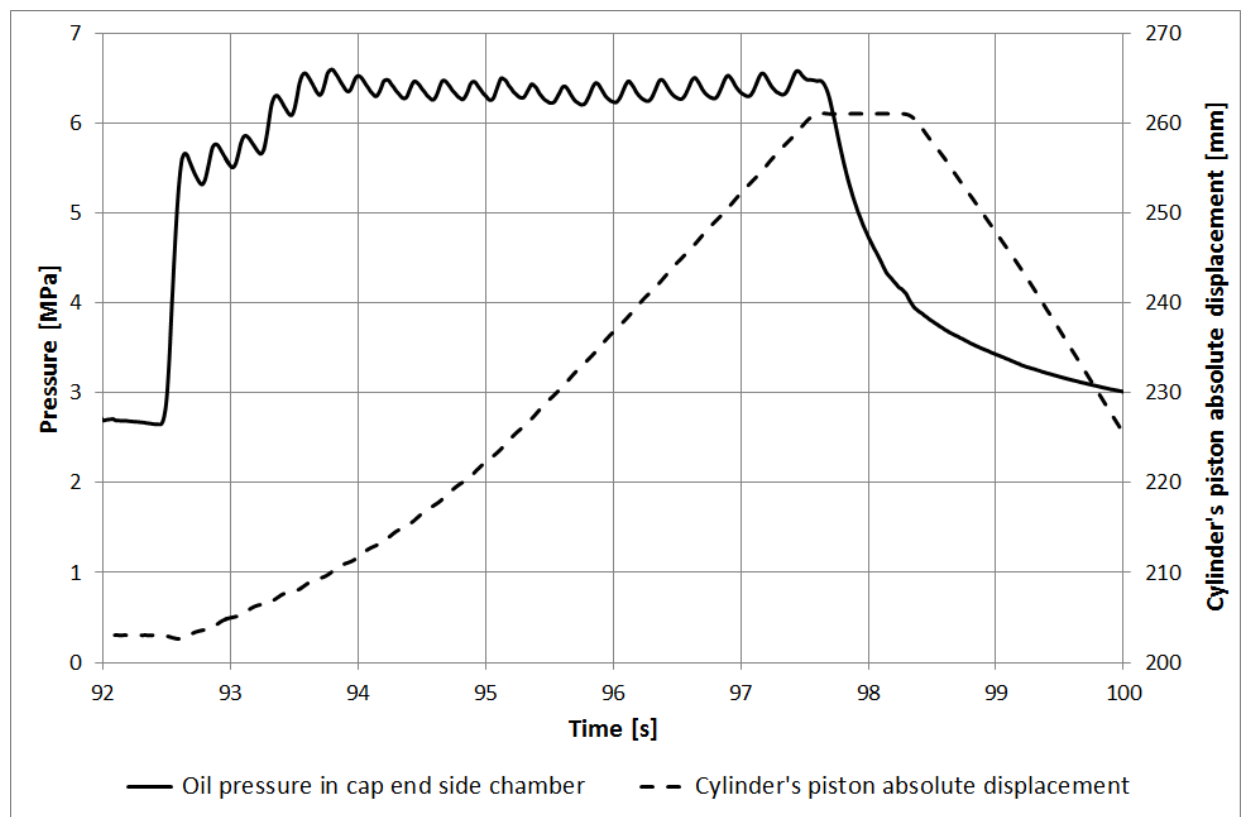

Fig. 3: Exemplary values measured during the LS control system tests in which the throttling valve No. 8 has been replaced with a check valve (description in the text).

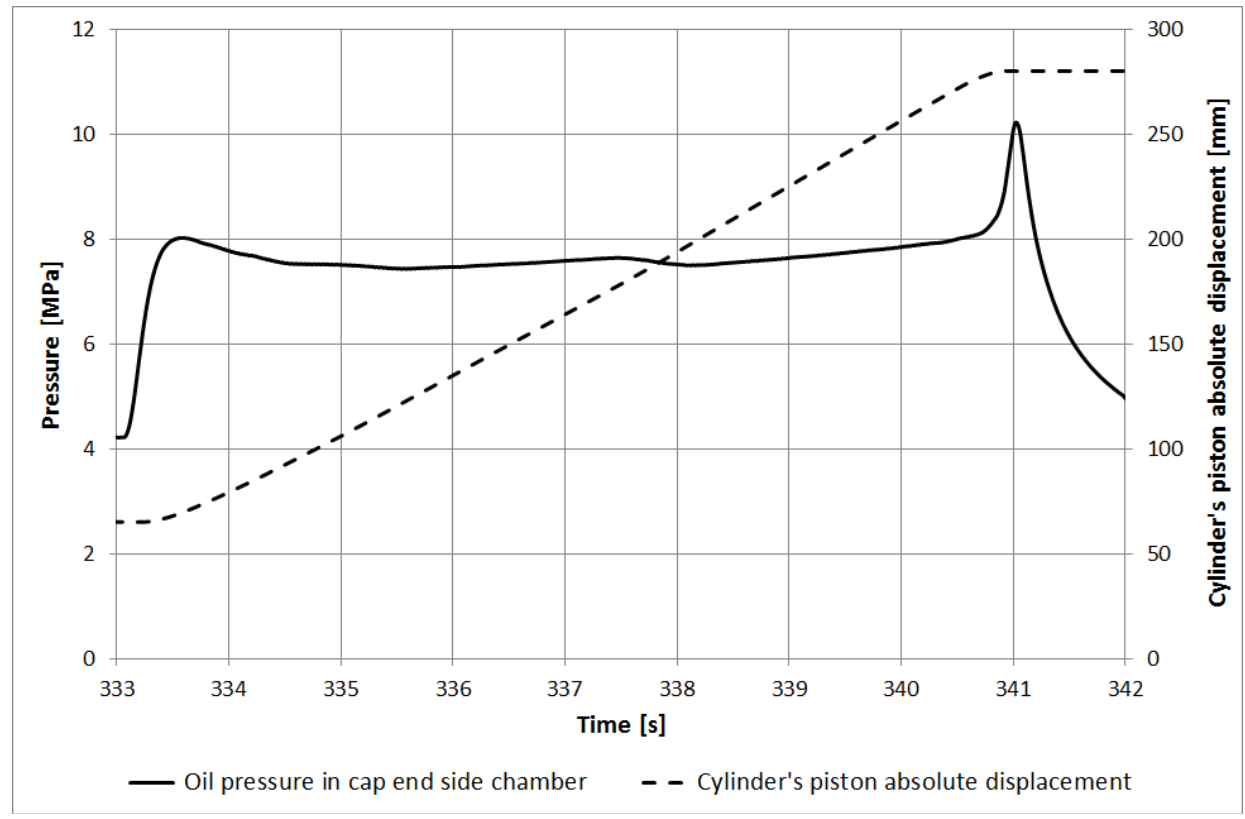

Fig. 4: Exemplary values measured during the tests of LS control system with a proportional valve PVG 32 equipped with a special design spool (description in the text).

\section{References}

Czabanowski, R. (2011) Deformable ground influence on the friction drive transmission between drive pulley and elastometric track. Journal of KONES, 2011, Vol. 18, No. 1, pp. 109-116

Dudziński, P. and Stefanow, D. (2016) The influence of dynamic soil parameters on tractive performance of offroad undercarriages. Journal of KONES, 2016, Vol. 23, No. 3, pp. 115-120

Dudziński, P. and Chołodowski, J. (2017) On internal resistance of rubber track systems. Proceedings of the 19th International \& 14th European-African Regional Conference of the International Society for Terrain-Vehicle Systems, September 25-27, 2017, Budapest (in Hungary).

Merritt, H. E. (1967) Hydraulic control systems. John Wiley \& Sons, Inc.

Nishida, Y. and Nihei, T. (2013) Introducing the HB335/HB365-1 Hybrid Hydraulic Excavators. Komatsu Technical Report, 2013, Vol. 59, No.166.

Szydelski, Z. (1999) Automobile vehicles. Hydraulic drive and control systems. WKiŁ, Warszawa. (in Polish) 